\title{
Research on the Hotspots of Ecological Sports
}

\author{
Xiangle Meng \\ Physical Education College of Yan'an University \\ Yan'an, China \\ Email:mz7006@126.com
}

\begin{abstract}
By the means of literature review method, this study combed the hotspots and its shortcomings of the ecological sports research in our country for more than 20 years of the research. The results show that the ecological development of sports culture, the development and utilization of sports ecological resources, and the Ecological Exploration of school physical education are the latest hotspots in the research of ecological sports. At the same time, there are many problems in research, such as the research method is single, repeated research, social sports and competitive sports research is lagging behind, the research system is not strong, etc. It is suggested that, on the basis of continuing to dig the existing hot issues, expanding the field of ecological sports research is needed urgently.
\end{abstract}

Keywords-ecological sports; research hotspots; research characteristics; deficiency

\section{INTRODUCTION}

Today, the ecological awareness has penetrated into many areas, has become the ecological concept of sublimation, so as to the physical field. Relevant researchers in the field of sports try to maintain and optimize the link of sports development and the environment, the development of sports and the surrounding environment. In the 1980s, researchers have already started preliminary exploration. Over the past 20 years, the ecological sports has become a hot topic of sports research. its research contents are gradually increasing, its research results are rich, and have formed a number of research hot spots.

\section{RESEARCH HOTSPOTS}

The understanding of the relationship between sports and ecology is from the initial focus on sports and the environment to explore the ecological development of sports culture, then to construct the theory of ecological sports, to explore school sports ecological teaching and to develop the preliminary construction of sports ecology.

\section{A. The development of Ecological sports culture}

Sports culture is an important part of the sports system, healthy sports culture is a necessary condition for the healthy development of sports. In our country, the research on the healthy development of sports culture has been paid more and more attention to the present situation of minority sports culture, to the construction of sports culture system and to the structure and characteristics of sports culture ecosystem. Such as "the Buyi original traditional sports culture research" [1], "Tujia dragon burning custom cultural ecology transformation and sports value of Xiangxi Ma Jing Ao town field investigation report". [2] These papers mainly studies the specific sports culture, expounded the origin, development and changes of specific cultural characteristics, value. At present, the similar researches are becoming rich, researchers investigate sports cultures from their own living environment or region, and analyze their local sports cultures and values, not only make other people understand the regional sports culture but also lay a solid foundation for heritage, sustainable development of many characteristic sports and sports culture.

Admittedly, protecting, inheriting and developing the inherent ecological sports culture has become increasingly important, but the constructing of ecological culture is more important, because it will play a leading role in developing sports system. Some scholars have done many studies on these. The paper of "the construction of sports cultures in view of ecological philosophy" described the present situation of the construction of sports culture, expounded the connotation of ecological sports cultural concept, and discussed the construction of ecological sports cultural. [3] Although the system of ecological sports culture construction is different from the concept of sports culture, but the paper pointed out that the sports cultural concept should include sports material culture, system culture and spiritual culture, it should cover all the contents of the sports culture. So the research is of considerable to have a great theoretical value. The paper of "The structure and characteristics of sports culture ecosystem" is a breakthrough model. [4] The study demonstrated "sports culture was ecological environment as well as ecological system", and defined the concept of the ecological system of physical culture, and then pointed out that the elements of the system included sports, symbols, native complex, historical inheritance, and the existence of ecological relationship between these elements. in a word, the sum of these relationships was the sports cultural ecological system. Compared with many scholars, The study have become a new starting point for further research.

\section{B. The exploitation and utilization of sports ecological resources}

China has a vast territory, its sports items and sports cultures are various, so combine sports with environmental resources diversity to form the sports ecological resources development is undoubtedly an important achievement in the process of ecological sports. The domestic research mainly involves two aspects: one is the ecological sports tourism research. Its contents include the feasibility and necessity of the development of ecological sports tourism, and the developing strategy of sports ecological tourism. The other is the ecological design and exploration of sports facilities. The 
design and development of the ecological sports venues are mainly related.

The paper of "The feasibility study on the development of ecological sports tourism in Lishui Baiyun Forest Park" is a typical exposition of the study of sports ecological tourism. [5] Based on the analysis of the tourism resources of Lishui Baiyun Forest Park, the paper pointed out that the advantages of its ecological sports tourism resources were biological landscape, leisure and fitness program, and the key to the development of ecological sports tourism in Baiyun Forest Park was to change the concept, to set up a comprehensive development organization, and to speed up the introduction of talents and fund.

Other research such as "ecological sports resources development and mode construction and application of Shandong Province -- Based on an empirical study" [6] , "The ecological environment construction under the background of Qinba mountain sports tourism development strategy research" [7] are also typical. They analyzed the status of different areas of the tourism environment, and discussed the feasibility and value of sport and tourism combining the proposed to promote the sustainable development of ecological sports tourism strategy. These studies are hot topics in recent years, and these studies will certainly play important roles in promoting the development of tourism resources and promoting the healthy development of sports.

\section{Exploration of ecological teaching in school physical education}

As early as 1996, china promulgated the "national environmental publicity and education action plan", which proposed in 2000, gradually carry out the establishment of the "green school" activities in country. Ecological school advocates that school sports education environment construction, education goal, curriculum design, education evaluation must meet ecological standards and environmental requirements. Researches focus on the construction of school sports ecosystem, the sustainable development of the ecological environment, the development strategy of the ecological environment and the reform and ecological development of the physical education curriculum resources. As the typical research "the construction of School sports ecology" [8], it pointed out that the ecological construction should include the implementation of construction of ecological thought and theory, the ecological sports course, the optimizing of the construction of ecological environment, the implementation of the school ecological sports culture campus. In fact, "the construction of the school ecological sports index system" [9] research has more research depth than previous articles'. The research established the system index of reflecting the school ecological sports, including 4 primary indexes, two 12 level indexes and three 68 level indexes. What' more, these indicators were admitted by experts, so, the research would provide the content and index model standard for evaluating school sports.

At the same time, a number of scholars launched some probes on how to construct the ecological school sports based on the cultural perspective, the school sports curriculum, the environment, or the ecological development of PE teachers. "Research on the school ecological environment of the middle school PE teachers' development" discussed the relationship between ecological environment and the development of PE teachers' healthy development, and the ways and methods of e PE teachers' ecological development. [10] Therefore, these researches are the development and refinement of school ecological sports.

\section{THE DEFICIENCY OF THE STUDY}

After 20 years of research and exploration, the ecological sports research results can be described as increasingly abundant, and research contents are from the ecological sports necessity and feasibility to create ecological sports science, 'then to the structure and function of sports ecosystem, even to establish index model of school sports ecological evaluation. However, if create a subject, the system theory be set up firstly, and then put the theory into practice. In the process of this paradigm, there are some shortcomings, such as using single research method, lacking of social sports research and systematical study of ecological sports and so on.

\section{A. Singularity of researching method}

Such a principle should be understood, that is, if a simple method can achieve the desired goal, why do have to use complex methods? In fact, adopting what kinds of methods are based on the needs of research, and not to say that a study on the use of advanced methods. In the overall study, the methods are literature and logical analysis method, inductive method and thinking method in 2004. Because in the early stage of research, people must first take use of the literature retrieval, collect related literatures, and then determine the contents by speculation. [11]

With the gradual deepening of the research, research should be from the macro level to the micro level, from speculation to empirical research. In this process, the literature method, the logical method and so on is suitable for the microcosmic, for the middle, and they should be the main body of the research methods. The micro level includes literature research method and the method is still applicable in part of middle level. However, research methods should be improved and diversified, especially the empirical research should be used. Part of the literature as previously cited, such as "construction of sports ecology ", mainly uses the method of literature, logical reasoning and induction. "Construction index system of ecological sports school" not only uses the method of literature and logical reasoning, but also the filter method. What's more, "Tujia dragon burning custom cultural ecology transformation and sports value of Xiangxi Ma Jing Ao town field investigation report", "the original ecological Buyi traditional sports culture research" used the field method, investigation method, interview method etc.

Therefore, with the deepening of the study, research methods should be varied according to the level and content of the different researches' needs, not only have the high-end theoretical research, but also have empirical research, then diverse research situation will arise, and this study rules appears early and widespread in sociology research. This is 
the viewpoint that is different to the " 21 years of China's sports ecology research review". [12] At present, the empirical research is not rich, not to say the further discussion of relevant theory.

\section{B. lack ecological research of social sports and competitive sports}

Although there are controversial, but social sports, competitive sports and school sports are the three major areas of sports is still widely accepted. From this point of view, the ecological sports process must be studied from the three major areas. According to researches, more researches paid attention to school sports field, including school sports ecological research necessity, ecological sports culture construction, school sports ecosystem construction, designing ecological subject content etc.

However, the research on social ecological sports is very few, and the main research is the ecological environment of the community sports, which belongs to the scope of the original ecological research. Competitive sports in china occupies a dominant position, is regarded as an important way to enhance the national strength, national strength and style, so it gets the support of the nation. Unfortunately, almost no one shows any interests in such an important field, Such as competitive sports system, sports culture, sports competitions, sports reserve talents of the ecological research is extremely scarce, so it is an obvious problem deserved to think deeply. For its reason, researchers' Identity and source are the main reasons: many scholars come from the school field, mainly engage in sports teaching and amateur training, they only familiar with the teaching and have no abilities or interests in the other two areas, so these scholars are more concerned about the related researches, and outputs is relative rich.

\section{The systematic research needs to be strengthened}

Before the research of ecological sports, it must be to understand that the ecological sports research refers to what. As far as I know, it refers to the theoretical and practical research done to make the development of sports meet the requirements of ecological development. After clarifying the scope of the study, we need to solve such a problem that where to start research, how to carry out research and how to transformation theory to $t$ practice.

For sports, its sub components consist of far more, such as sports culture, sports system, sports programs, sports talents, sports organizations, sports competitions and so on. Therefore, we can start respectively from these sub components to make these components ecological, analyze and define their concepts, functions and structures of the system, finally is to explore the ways and Strategies of all the components of the ecological. As far as the current research is concerned, There are many breakthroughs in the study, such as defines the research scope and methods, principles, approaches for the study of sports in certain field, and even builds a solid foundation for the follow-up research subject. However, after these groundbreaking researches, follow-up researches are rare, even those high quality of production scholars turn to other research content, this is one of the causes that make related researches neither systematic nor deep. Other researches show that researchers are completely to see what the research focus are, and then follow the trend of learning. So the present study is far from covering the field of sports, is concentrated on a few hot spots, those not involved or rarely involved research contents are snubbed, resulting too much repeated studies. All of these show that innovative thinking and courage spirit has not appeared, and highlighting the awkward transplant of research paradigm and discipline knowledge.

\section{CONCLUSION}

Overall, future research must be based on the existing achievements in succession, try our best to use research methods rationally, to combine theoretical analysis with empirical test, to expand and deepen research. What's more, we should especially pay more attention to the reconstruction of ecological Science, to the reflection after the practice of sports ecology.

\section{REFERENCES}

[1] Yaqiong Wang, Jianxin Luo. Study of Buyi original traditional sports culture of [J]. Agricultural Archaeology, 2011, 4:124-128.(In chinese)

[2] Jinxiang Bai, Jianwen $\mathrm{Hu}, \mathrm{Yi}$ Wan, Tujia dragon burning custom cultural ecology transformation and sports value of Xiangxi Ma Jing Ao town field investigation report [J]. Journal of physical education, 2009 , 16 (10): 94-97. (In chinese)

[3] Mingzhi Lu, Xiaohong Zhang. The sports cultural construction based on the view of ecological philosophy $[\mathrm{J}]$. Liaoning sports science and technology, 2007, 29 (5): 5-6. (In chinese)

[4] Jianlin Gong. The structure and characteristics of sports culture ecosystem [J].Journal of 2011, 18 (4): 40-44. (In chinese)

[5] Guangyu Song, Dilei Song. Feasibility study on the development of ecological sports tourism in Lishui Baiyun Forest Park [J]. Zhejiang sports science, 2011, 33 (1): 18-21. (In chinese)

[6] Junhua Zhou, Han Sun. Research on the development and construction of ecological sports resources and Its Application Research-a case study of Shandong province [J]. Journal of Shandong Sports Institute, 2010, 26 (7): 8-12. (In chinese)

[7] Liang $\mathrm{Xu}$. Research on the development strategy of sports tourism in Qin Ba mountain area under the background of ecological environment construction in Western China [J]. Journal of Beijing Sport University, 2008, 31 (11): 1475-1478. (In chinese)

[8] Xinhua Zhu. On the construction of the school sports ecology [J]. Fujiansports science and technology, 2010, 29 (3): 52-54. (In chinese)

[9] Hui Lei, Luoping Deng, Tiexiong Zhang. Construction of the index system of school ecological sports [J]. Journal of Wuhan Sports Institute, 2008, 42 (9): 28-31. (In chinese)

[10] Chuanming Cai. Study on the ecological environment of the middle school physical education teachers' growth [D]. Fuzhou: Fujian Normal University, 2007:72-76. (In chinese)

[11] Liwei Zhang. Qualitative research can be made of sports science doctoral thesis? [J]. Journal of Beijing Sport University, 2002, 25 (6): 0781-0783. (In chinese)

[12] Xuejun Liu. Review of sports ecology research in China [J]. Journal of Zhejiang College of Education, 2010(5): 105-112. (In chinese) 